\title{
Repair of Radial Meniscus Tears Results in Improved Patient-Reported Outcome Scores: A Systematic Review
}

\author{
Eric M. Milliron, B.S., Robert A. Magnussen, M.D., M.P.H., Parker A. Cavendish, B.S., \\ John P. Quinn, B.S., Alex C. DiBartola, M.D., M.P.H., and David C. Flanigan, M.D.
}

\begin{abstract}
Purpose: To quantify healing rates and patient-reported outcome scores following repair of radial meniscus tears. Methods: PubMed, Scopus, and Embase databases were searched according to Preferred Reporting Items for Systematic Reviews and Meta-Analyses (PRISMA) guidelines. Inclusion criteria included: human subjects with meniscal tears, fulltext English language, average follow-up of at l year, and publication after the 2000. Exclusion criteria included technical, biomechanical, and cadaveric studies. Study quality was assessed using Coleman Methodology Scores and Methodological Index for Non-Randomized Studies (MINORS) criteria. Results: Twelve studies reported on the repair of 243 radial tears in 241 patients. The mean Modified Coleman Methodology Score was 46.8, range 26-60, with a mean level of evidence of 3.5. Arthroscopic techniques were used in all studies, with 1 study using an arthroscopic-assisted 2-tunnel transtibial pullout technique. The mean patient age was 32 years (11-71). The mean follow-up was 35 months (12 to 75.6 ). The average time to surgery was 10.9 months (0.5-22.4). Eight of the 12 studies reported concomitant anterior cruciate ligament (ACL) reconstruction, with 64\% having concomitant ACL injury. The most common outcome measure was the Lysholm score, which improved from 47-68.9 preoperatively to 86.4-95.6 postoperatively. Tegner Activity Scale improved from 2.53.1 preoperatively to 4.7-6.7 postoperatively. Healing rates were reported via magnetic resonance imaging and second-look arthroscopy. Second-look arthroscopy was performed for a variety of indications, including removal of screw, washers or plates, dissatisfaction with original procedure, partial healing found on magnetic resonance imaging, or desire of the patient to know the true healing status before return to sport. Of those assessed, $62.0 \%$ had complete healing, $30.0 \%$ partial healing, and $8.0 \%$ failure to heal. Conclusions: Patient-reported outcomes of radial meniscus repair with and without ACL reconstruction are encouraging, with high patient-reported outcomes reported at final follow-up when compared with preoperative scores. Among all meniscus repairs assessed for healing, the majority demonstrated at least some healing with an overall low rate of failure. Level of Evidence: IV; systematic review of level III-IV studies.
\end{abstract}

$\mathbf{T}$ he meniscus is a complex, soft-tissue structure composed of a high amount of fluid and a specialized extracellular matrix. ${ }^{1,2}$ Its function is vital for both stability and overall health of the knee joint. ${ }^{1}$ Meniscal injury remains one of the most common knee injuries presented to orthopaedic surgeons. ${ }^{3}$ At an estimated 850,000 surgeries performed on the meniscus annually, ${ }^{4}$ management of these injuries is of great importance within the field. Within recent years,

From the College of Medicine (E.M.M., P.A.C., J.P.Q.); Department of Orthopaedics (R.A.M., A.C.D., D.C.F.); Sports Medicine (R.A.M., D.C.F.); and Cartilage Restoration Program (D.C.F.), Ohio State University Wexner Medical Center, Columbus, Ohio, U.S.A.

The authors report the following potential conflicts of interest or sources of funding: D.C.F. reports grants and other from Smith $\theta$ Nephew, Zimmer Biomet, and Vericel; other from MTF, KCRN, and Hyalex; grants and other from CartiHeal, Anika Therapeutics, Aesculap, and Moximed, outside the submitted work. Full ICMJE author disclosure forms are available for this article online, as supplementary material. there has been a shift in the paradigm of approach to meniscus injuries. ${ }^{5}$ As evidence continues to show an association between meniscectomy and osteoarthritic changes over time, ${ }^{6-8}$ the focus on preservation of meniscal tissue has become increasingly imperative. This general shift in approach to meniscal injury has led to the emergence of arthroscopic repair techniques as gold standard for management of many tear types.

Received July 20, 2020; accepted March 4, 2021.

Address correspondence to David C. Flanigan, M.D., OSU Sports Medicine, 2835 Fred Taylor Drive, Columbus, OH 43202. E-mail: david.flanigan@ osumc.edu

(C) 2021 THE AUTHORS. Published by Elsevier Inc. on behalf of the Arthroscopy Association of North America. This is an open access article under the CC BY-NC-ND license (http://creativecommons.org/licenses/by-nc-nd/4.0/).

2666-061X/201278

https://doi.org/10.1016/j.asmr.2021.03.002 
Classification of tears over time has led to a better understanding of the optimal means of surgical management. ${ }^{10}$ Common types such as longitudinal or horizontal tears can be treated arthroscopic repair with excellent results. ${ }^{11-13}$ Conversely, radial meniscus tears are a subtype of meniscus injury that has historically been associated with poor prognosis. Factors contributing to this prognosis include a loss of hoop stress, decreased tibiofemoral contact area, and unfavorable dynamic contact pressures. ${ }^{14}$ It was formerly thought that radial tears did not lend themselves well to surgical repair, and these tears were generally treated with partial meniscectomy. Despite the aforementioned shift in paradigm, the management of radial tears has seemingly lagged behind the other classes of tears. As the literature continues to be updated with studies focused on repairing radial tears and the outcomes following such procedures, it is worth re-examining the current state of surgical repair of radial tears, and associated outcomes.

Through search of the literature, 2 other systematic reviews focused on radial meniscus repair were found. Moulton et al. ${ }^{15}$ conducted a review of 6 studies and concluded that radial meniscus repair produced satisfactory outcomes in the short term. Lee et al., ${ }^{16}$ in review of 17 studies focused solely on repair of medial meniscus posterior root tears, similarly discovered improvement in clinical outcomes. Although these reviews effectively establish the value in repairing radial meniscus tears, neither explicitly report on subsequent healing rates of the meniscus, a vital aspect of better understanding outcomes. Therefore, we performed a systematic review of published literature to help further inform clinician decision making when considering the approach to radial meniscus tears. The purpose of this study is to quantify healing rates and patient-reported outcome scores following repair of radial meniscus tears. We hypothesized that radial meniscus repair would result in high healing rates and improvement in patient-reported outcome measures from preoperative.

\section{Methods}

\section{Search Strategy and Selection Criteria}

A systematic search of the medical literature was conducted in the PubMed, Embase, and Scopus
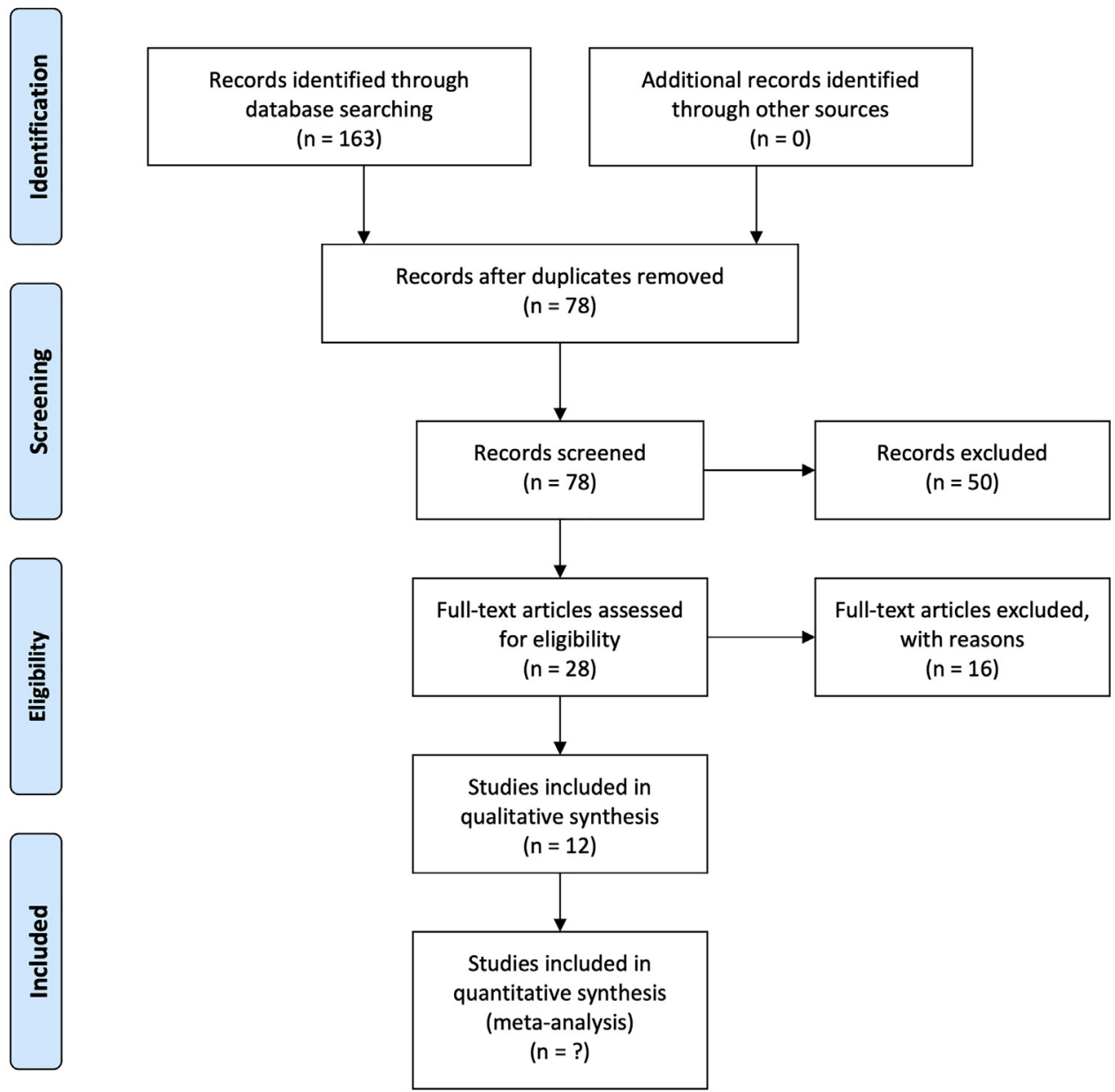

Fig 1. Preferred Reporting Items for Systematic Reviews and Meta-Analyses (PRISMA) flow diagram outlining algorithm for study inclusion and exclusion. 


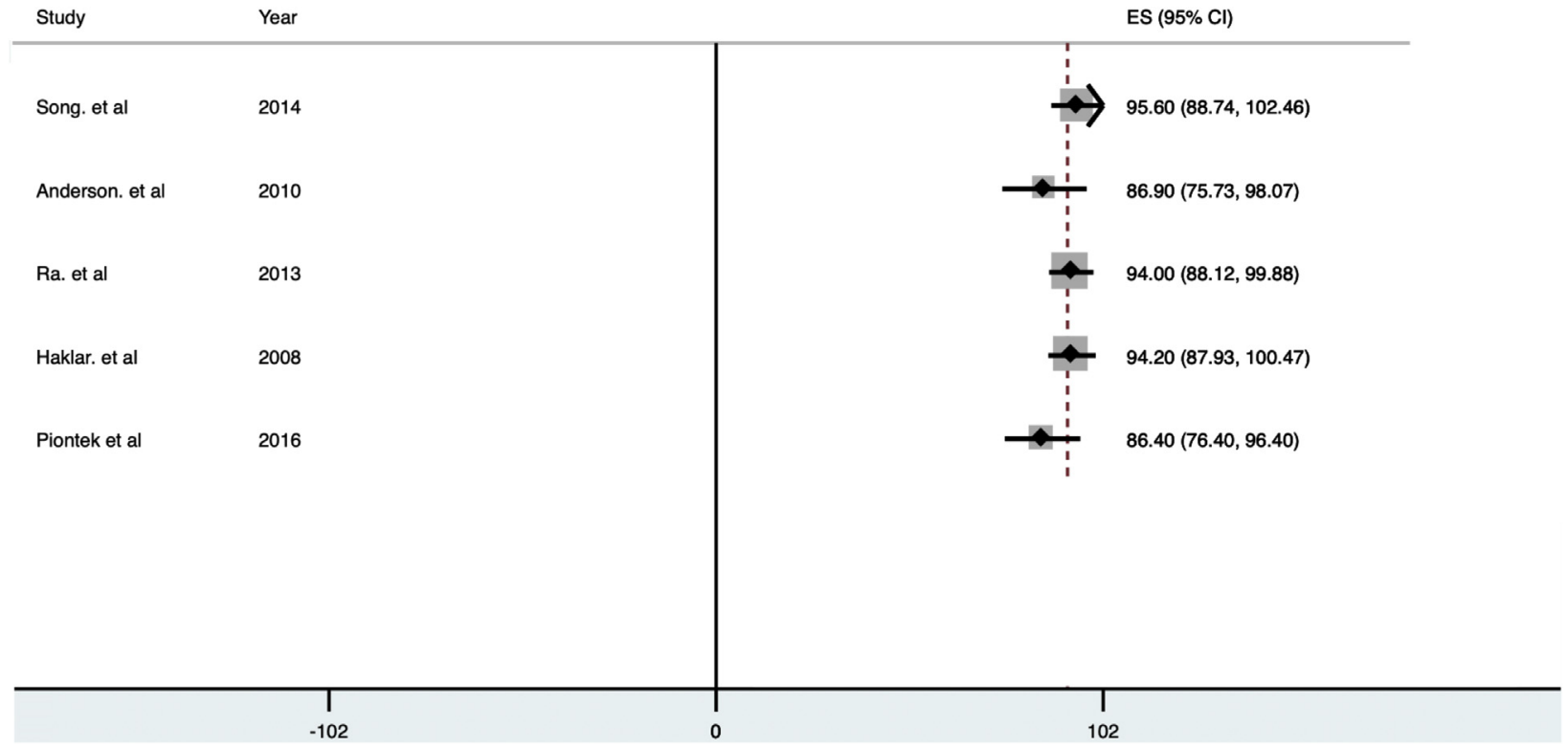

Fig 2. Forest plot of preoperative Lysholm knee scores. (CI, confidence interval; ES, effect size.)

databases in accordance with the guidelines set for standardized reporting of systematic reviews by the Preferred Reporting Items for Systematic Reviews and Meta-Analyses (PRISMA) statement to identify studies that assessed outcomes following radial meniscus repair. ${ }^{17}$ All studies generated from the search criteria were independently reviewed for inclusion by 2 authors, E.M.M. and J.Q., with disagreements on article inclusion mediated by a third author, P.C. Included studies were published in English since the year 2000 with a minimum mean follow-up of 12 months after radial meniscus repair. Only articles published in the last 20 years were eligible for inclusion to minimal heterogeneity due to changes in repair techniques over time. This date was arbitrarily chosen.

\section{Study Selection and Data Extraction}

An initial search (January 28, 2020) of PubMed, Embase, and Scopus databases yielded a total of 78 unique articles (search terms, ("radial"[All Fields] OR "radially" [All Fields] OR "radials"[All Fields]) AND ("meniscus" [MeSH Terms] OR "meniscus"[All Fields] OR "menisci"[All Fields]) AND ("repairability" [All Fields] OR "repairable"[All Fields] OR "repaire"[All Fields] OR "repaired"[All Fields] OR "repairment" [All Fields] OR ("healing" [All Fields]) OR "repair"[All Fields] OR "repairing"[All Fields] OR "repairs"[All Fields]) AND ("outcome"[All Fields] OR "outcomes"[All Fields]). These articles were independently screened by title and abstract based on the inclusion and exclusion criteria. Included studies were

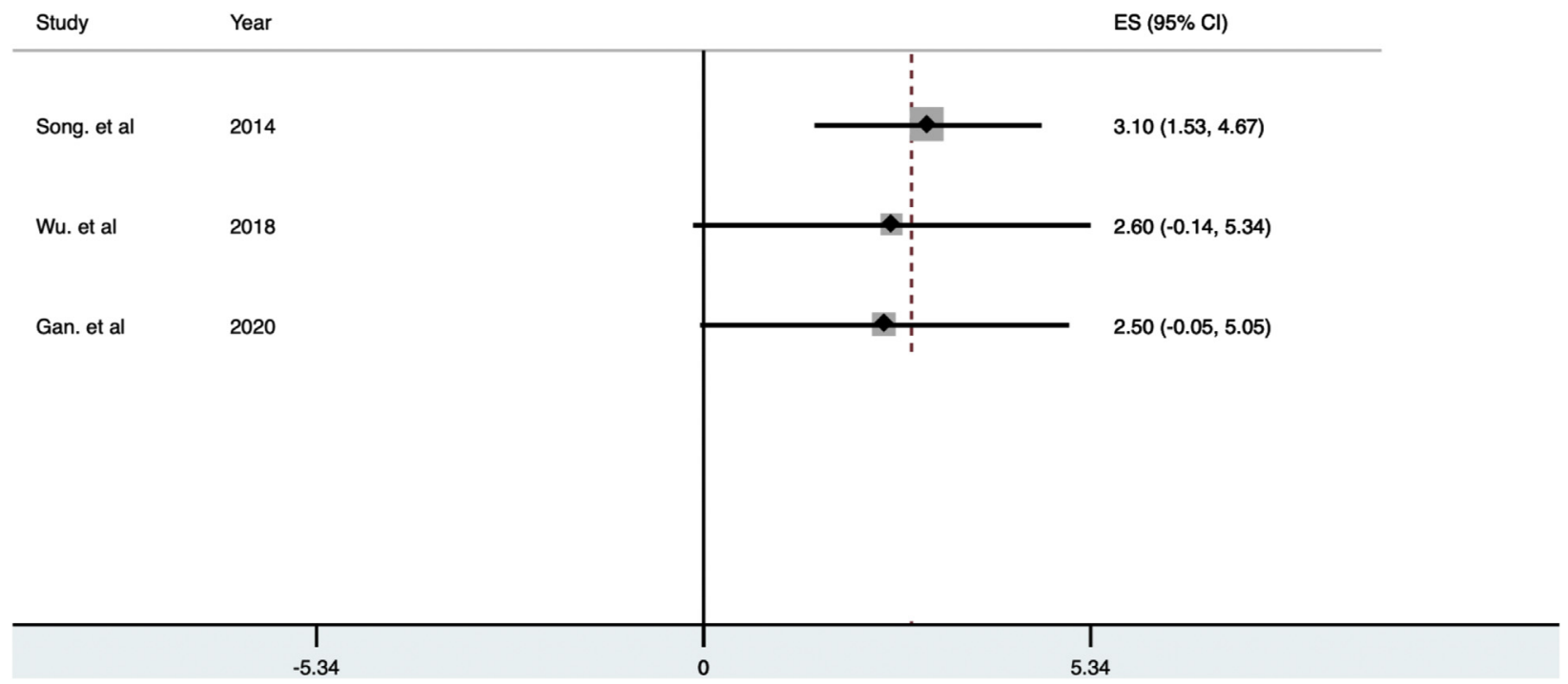

Fig 3. Forest plot of postoperative Lysholm knee scores. (CI, confidence interval; ES, effect size.) 


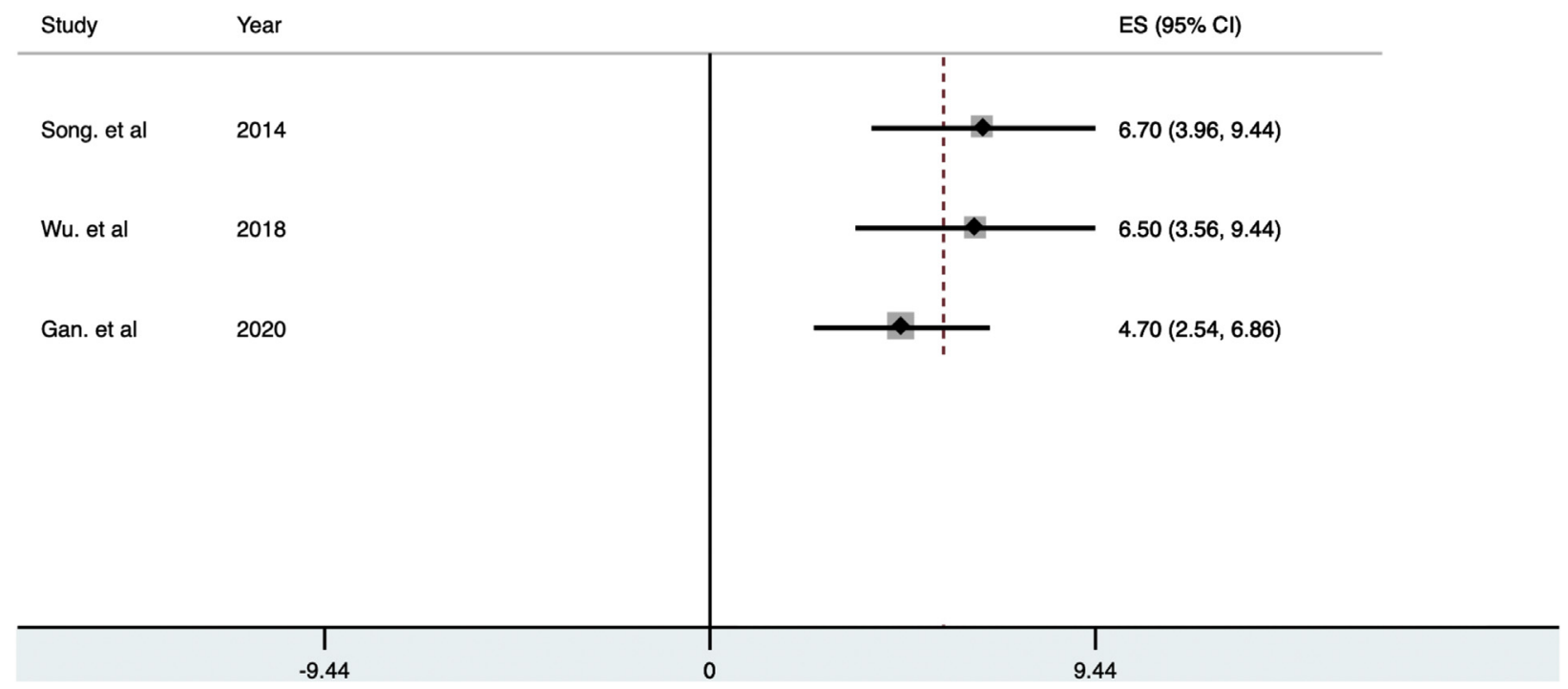

Fig 4. Forest plot of preoperative Tegner knee scores. (CI, confidence interval; ES, effect size.)

those with human subjects, tears of the medial or lateral meniscus, or both, full-text English manuscripts, follow up of at least 12 months, all levels of evidence and published after the year 2000. Studies were excluded if they were technical notes or biomechanical or cadaveric studies. The initial screen eliminated 50 studies, and 28 studies remained for full-text analysis. Full-text analysis against the inclusion and exclusion criteria resulted in 12 studies on radial meniscus repair being suitable for inclusion (Fig 1). ${ }^{18-29}$ Two authors, E.M.M. and J.Q., independently extracted and recorded outcomes data following radial meniscus repair from the 12 articles. Extracted data included patient-reported outcomes as well as rates of reoperation and status of repair assessed by magnetic resonance imaging (MRI) or second-look arthroscopy.

\section{Methodologic Quality and Bias Assessment}

Study methodologic analysis was completed using the Modified Coleman Methodology Score system. ${ }^{30}$ The maximum score is 100 , with scores greater than 85 defining an excellent study, 70 to 84 a good study, 55 to 69 a fair study, and less than 55 a poor study (Table 1). Based on the criteria set by the Centre for EvidenceBased Medicine on the levels of evidence for therapeutic studies, included studies ranged from Level II through Level IV evidence. ${ }^{31}$ Because all included studies were nonrandomized, risk of bias was appraised

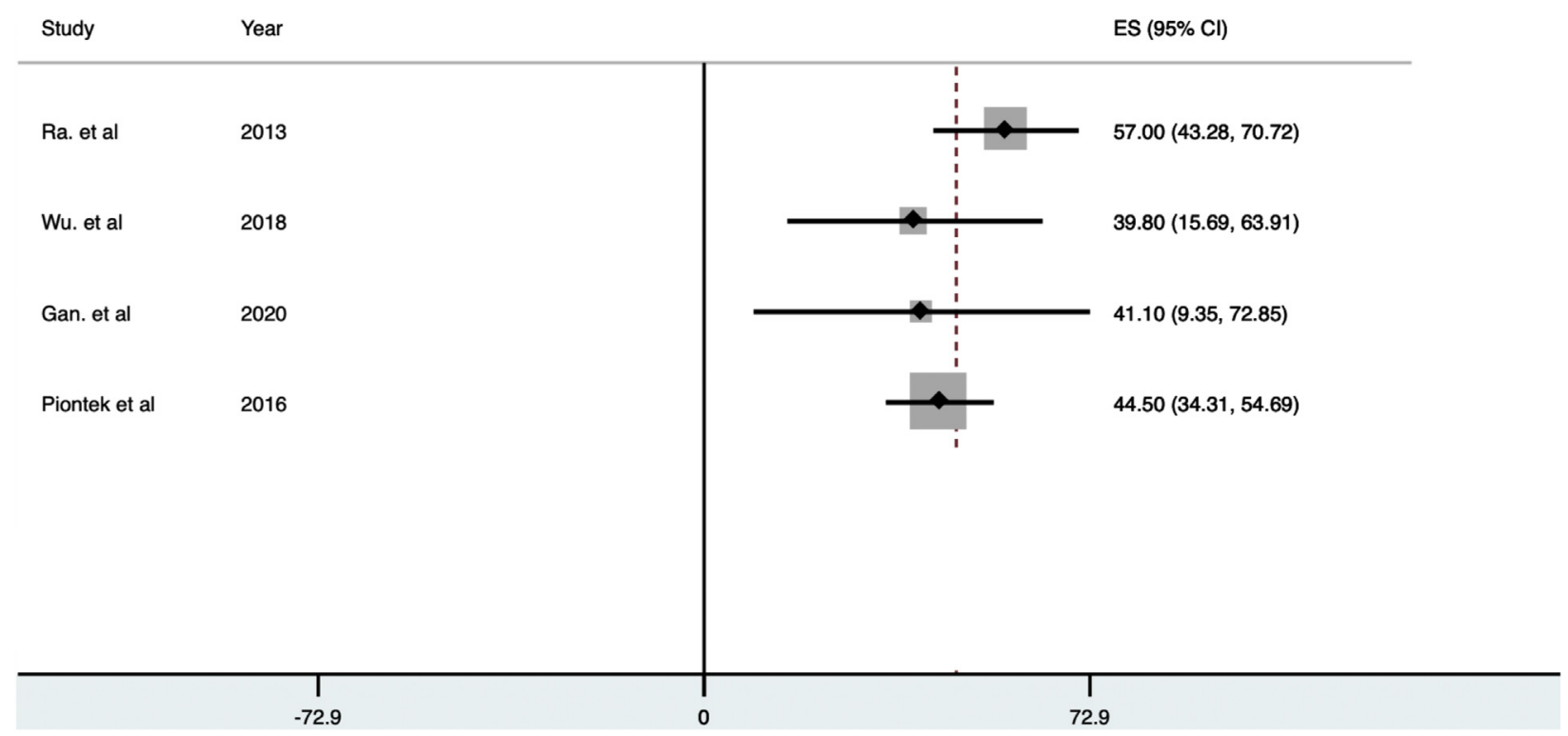

Fig 5. Forest plot of postoperative Tegner knee scores. (CI, confidence interval; ES, effect size.) 


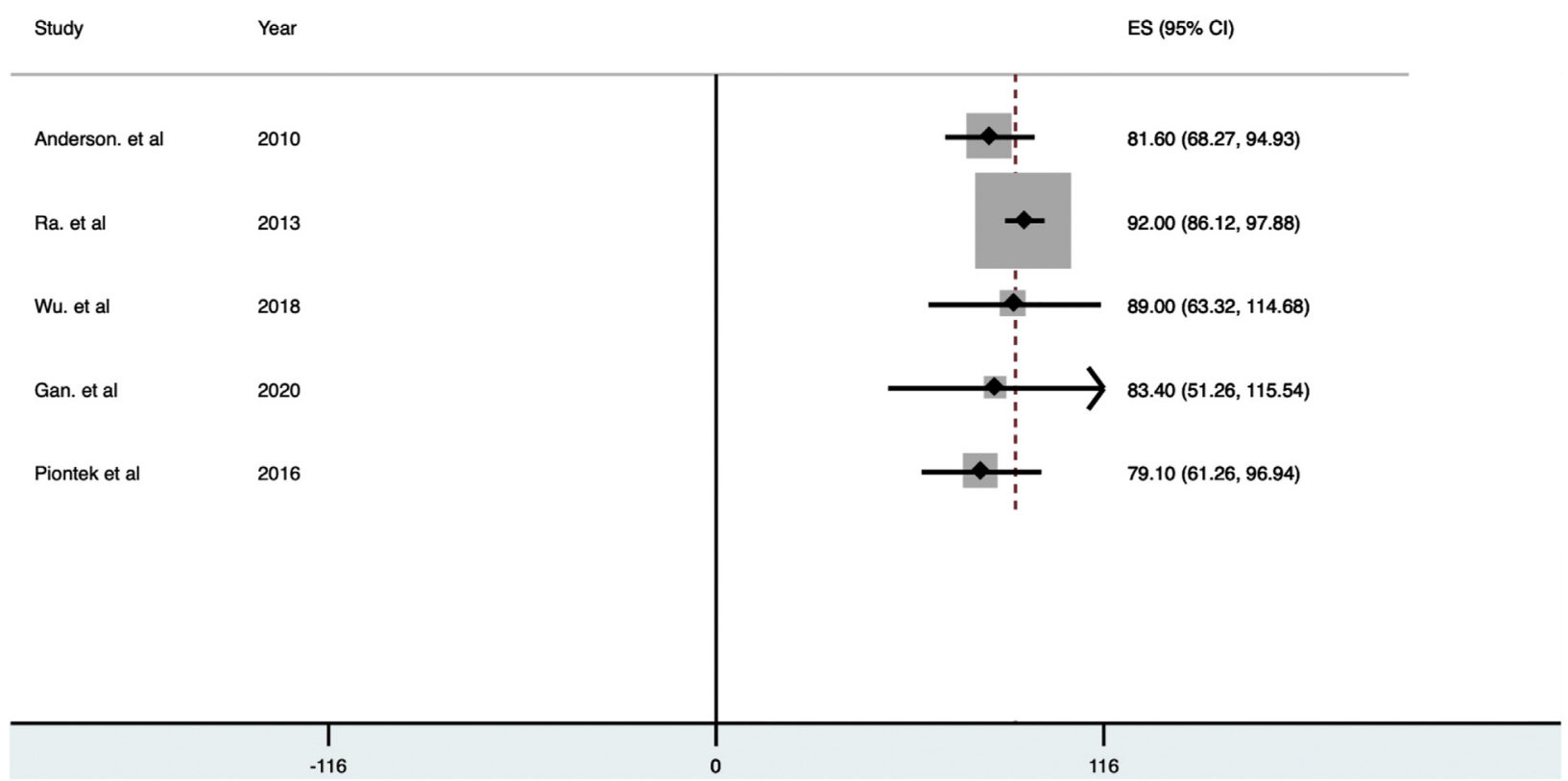

Fig 6. Forest plot of preoperative IKDC knee scores. (CI, confidence interval; ES, effect size; IKDC, International Knee Documentation Committee;)

for each study using the Cochrane Risk of Bias In Nonrandomized Studies-of Interventions (ROBINS-I) tool (Table 2). ${ }^{32}$

\section{Statistical Analysis}

Descriptive statistics were generated and summarized for all study characteristics. Ranges were reported for outcomes scores where appropriate (Figs 2-7). Statistical analyses were performed with STATA 14.0 (StataCorp, College Station, TX).

\section{Results}

\section{Study Characteristics}

An initial search (January 28, 2020) of PubMed, Embase, and Scopus databases yielded a total of 78 unique articles. The initial screen eliminated 50 studies, and 28 studies remained for full-text analysis. Full-text analysis against the inclusion and exclusion criteria resulted in 12 studies on radial meniscus repair being suitable for inclusion (Fig 1). ${ }^{18-29}$ Two authors, E.M.M.

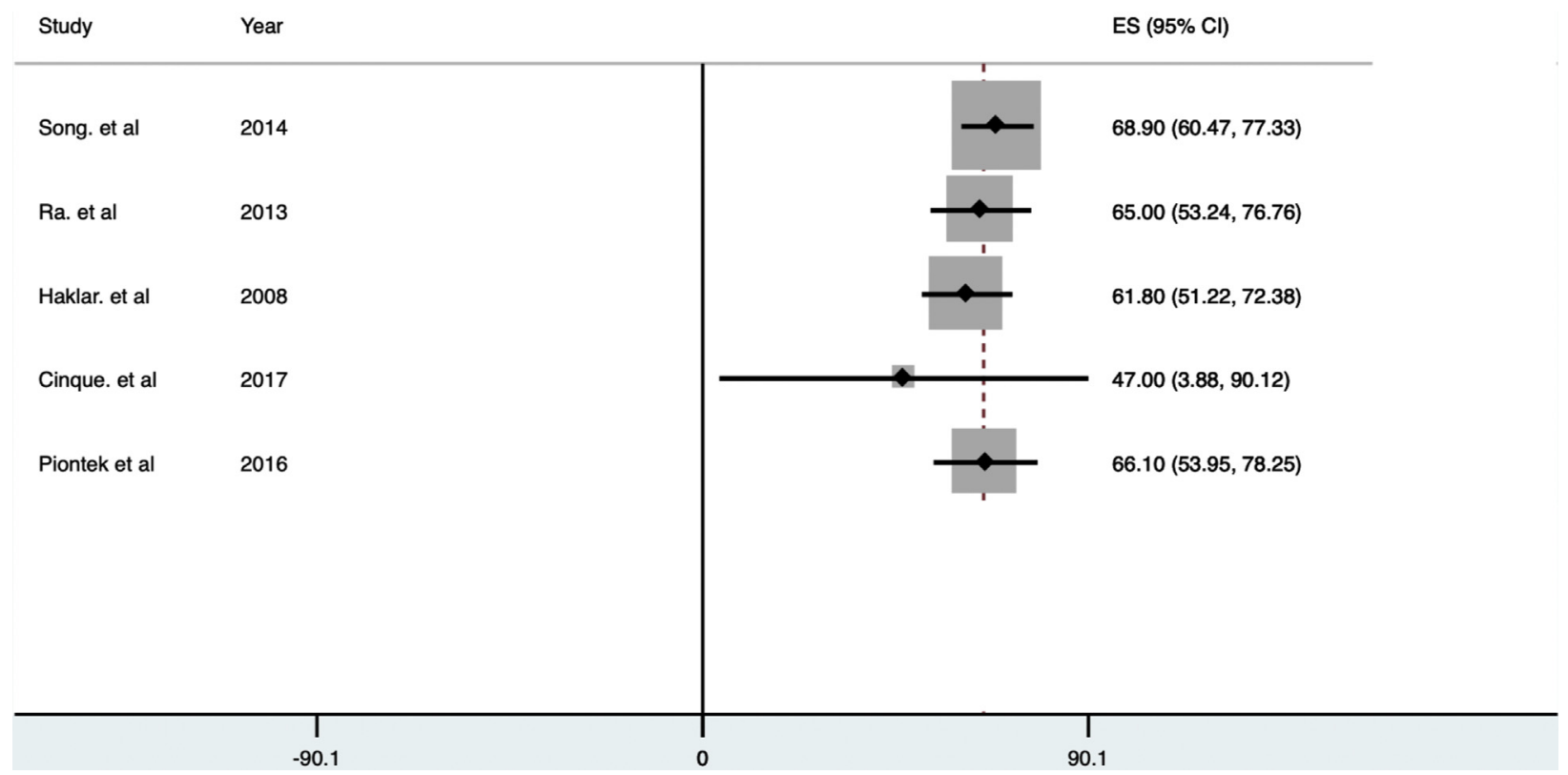

Fig 7. Forest plot of postoperative IKDC knee scores. (CI, confidence interval; ES, effect size; IKDC, International Knee Documentation Committee; ) 


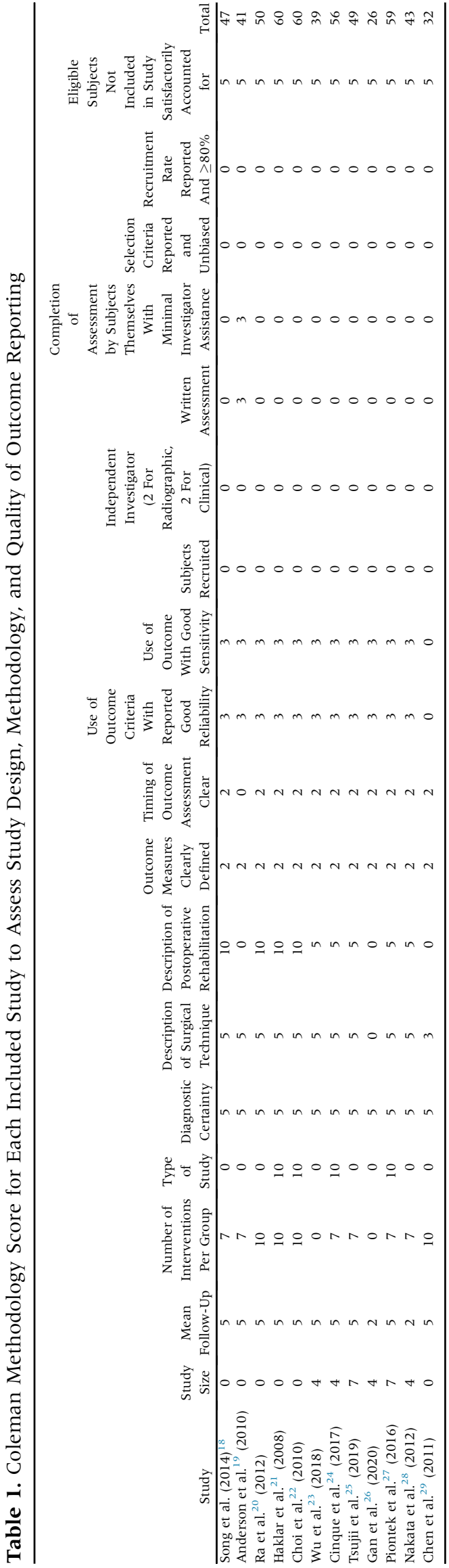

and J.Q., independently extracted and recorded outcomes data following radial meniscus repair from the 12 articles. The earliest year of publication was 2008 and the most recent year of publication was 2020, with all operations taking place between 1994 and 2016. All studies were single-center studies across a range of countries in Europe, Asia, and North America. None of the studies were randomized. Study design included 5 retrospective cohort studies, one case control study, and 6 case series (Table 3 ).

\section{Methodologic Quality}

The mean Modified Coleman Methodology Score for the 12 included studies was 46.8, range 26-60 (Table 1). Four of 12 studies received a score between 55 and 69 indicating fair studies, with the remaining 8 of 12 studies falling below a score of 55 indicating poor studies. Areas largely contributing to the mean score include, study size, the type of study, and scores related to subject recruitment and selection. Six of 12 studies did not include enough patients undergoing radial meniscus repair to receive a score $>0$ in size. Eight of 12 studies received a score of 0 in study type due to their retrospective analysis, and because no randomized control trials were included, 12 of 12 studies received a score of 0 in subject recruitment, using independent investigators, unbiased selection criteria, and recruitment rate.

\section{Bias Assessment}

Bias appraisal was completed using the ROBINS-I tool (Table 2). Of the 12 studies included, 8 of 12 had a serious overall risk of bias, defined as a serious risk of bias in at least 1 domain. Four of 12 had a moderate overall risk of bias, defined as low or moderate risk of bias for all domains. Per the bias tool, all studies with a serious overall risk of bias are noted to have some important problems, whereas all studies with a moderate overall risk of bias are noted provide sound evidence for a nonrandomized study that cannot be considered comparable to a well-performed randomized study. The majority of studies $(8 / 12)$ were assessed to have a serious risk of bias due to confounding, meaning that at least one important domain was not appropriately measured or controlled for. As it relates to bias in selection and bias in classification of interventions, 7 of 12 and 10 of 12 were assessed to be of moderate risk of bias, respectively. The majority of studies were assessed to have a low risk of bias due to deviations from intended interventions $(9 / 12)$, due to missing data $(10 / 12$, and due to bias in the selection of the reported result (11/12).

\section{Patient Characteristics}

Within the 12 included studies, there were 243 operated knees in 241 patients (Table 4). The mean 
Table 2. Bias Assessment Using the Cochrane Risk of Bias in Non-Randomized Studies - of Interventions (ROBINS-I) Tool

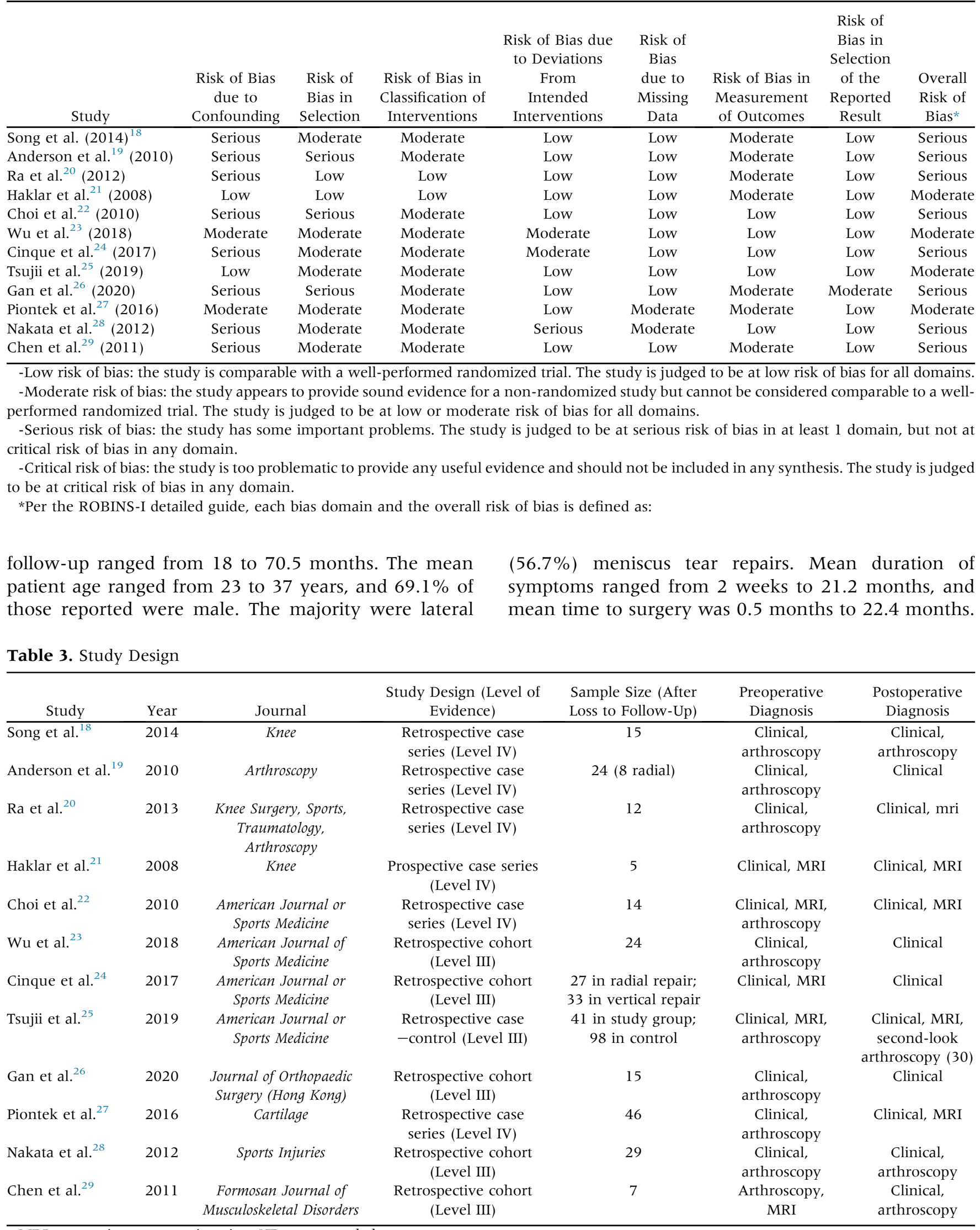


Table 4. Patient Characteristics

\begin{tabular}{|c|c|c|c|c|c|c|c|c|c|c|c|c|c|}
\hline Study & $\begin{array}{c}\text { Initial } \\
\text { Sample } \\
\text { Size }\end{array}$ & $\begin{array}{c}\text { Knees With } \\
\text { Follow-Up } \\
(\%)\end{array}$ & $\begin{array}{c}\text { Mean } \\
\text { Follow-Up }\end{array}$ & $\begin{array}{l}\text { Lost to } \\
\text { Follow-Up }\end{array}$ & Mean Age, y & $\begin{array}{c}\text { Sex } \\
\text { (Male) }\end{array}$ & Laterality & $\begin{array}{l}\text { Meniscus } \\
\text { Involved }\end{array}$ & $\begin{array}{c}\text { Tear } \\
\text { Grade }\end{array}$ & $\begin{array}{c}\text { No. With } \\
\text { Previous } \\
\text { Surgery }\end{array}$ & $\begin{array}{c}\text { No. With } \\
\text { Concomitant } \\
\text { ACLR }\end{array}$ & $\begin{array}{c}\text { Mean } \\
\text { Duration } \\
\text { of } \\
\text { Symptoms }\end{array}$ & $\begin{array}{l}\text { Mean Time } \\
\text { to Surgery }\end{array}$ \\
\hline$\overline{\text { Song et al. }{ }^{18}}$ & NR & $15(\mathrm{NR} \%)$ & $\begin{array}{c}24 \text { months } \\
(12-46)\end{array}$ & $\mathrm{NR}$ & $34.5(18-56)$ & 12 & NR & $\begin{array}{c}15 \text { Lateral } \\
0 \text { Medial }\end{array}$ & NR & NR & 15 & NR & 3.3 months \\
\hline Anderson et al. ${ }^{19}$ & 8 & $8(100 \%)$ & $\begin{array}{c}70.5 \text { months } \\
(29-168)\end{array}$ & 0 & NR & 5 & $\begin{array}{l}3 \text { Left } \\
5 \text { Right }\end{array}$ & $\begin{array}{l}8 \text { Lateral } \\
0 \text { Medial }\end{array}$ & NR & NR & 8 & NR & $\begin{array}{c}22.4 \\
\text { months }\end{array}$ \\
\hline Ra et al. ${ }^{20}$ & 27 & $12(44 \%)$ & $\begin{array}{c}30 \text { months } \\
(26-34)\end{array}$ & $\begin{array}{l}27 \text { total at } \\
\text { beginning } \\
\text { (15 lost to } \\
\text { follow-up) }\end{array}$ & NR & 11 & NR & $\begin{array}{l}9 \text { Lateral } \\
3 \text { Medial }\end{array}$ & NR & NR & 2 & NR & NR \\
\hline Haklar et al. ${ }^{21}$ & 5 & $5(100 \%)$ & $\begin{array}{l}31 \text { Months } \\
(12-46)\end{array}$ & 0 & $28.6(17-35)$ & NR & $\begin{array}{l}3 \text { Left } \\
2 \text { Right }\end{array}$ & $\begin{array}{l}5 \text { Lateral } \\
0 \text { Medial }\end{array}$ & NR & NR & 0 & 2 weeks & 2 weeks \\
\hline Choi et al. ${ }^{22}$ & 21 & $14(67 \%)$ & $\begin{array}{l}36.3 \text { months } \\
(24-54)\end{array}$ & $\begin{array}{c}21 \text { total at } \\
\text { beginning (7 } \\
\text { lost to } \\
\text { follow-up) }\end{array}$ & $29.9(16-52)$ & 11 & NR & $\begin{array}{c}14 \text { Lateral } \\
0 \text { Medial }\end{array}$ & NR & NR & 0 & $\begin{array}{c}6 \text { months } 3 \\
\text { days }\end{array}$ & $\begin{array}{l}6.75 \\
\text { months }\end{array}$ \\
\hline Wu et al. ${ }^{23}$ & 38 & $31(82 \%)$ & $\begin{array}{l}42 \text { months } \\
(24-76)\end{array}$ & 7 & $22.8 \pm 11.9$ & 18 & NR & $\begin{array}{l}28 \text { Lateral } \\
3 \text { Medial }\end{array}$ & NR & 0 & 16 & NR & $\begin{array}{c}48 \pm 62 \\
\text { days }\end{array}$ \\
\hline Cinque et al. ${ }^{24}$ & 27 & $27(100 \%)$ & $\begin{array}{l}42 \text { months } \\
(24-65)\end{array}$ & 0 & $35.1(18-67)$ & 19 & $\begin{array}{l}16 \text { Left } \\
11 \text { Right }\end{array}$ & $\begin{array}{l}1 \text { Lateral } \\
26 \text { Medial }\end{array}$ & NR & 0 & 17 & NR & $\mathrm{NR}$ \\
\hline Tsujii et al. ${ }^{25}$ & 41 & $41(100 \%)$ & 41 months & 0 & $29.5(14-57)$ & 18 & NR & NR & NR & NR & 41 & NR & 124.8 days \\
\hline Gan et al. ${ }^{26}$ & 15 & $15(100 \%)$ & 22.4 months & 0 & 42 & NR & NR & NR & NR & NR & NR & NR & NR \\
\hline Piontek et al. ${ }^{27}$ & 58 & $53(91 \%)$ & $>24$ months & $\begin{array}{l}3 \text { (2 others } \\
\text { dropped from } \\
\text { study due to } \\
\text { data missing }\end{array}$ & $36.7(18-59)$ & 36 & $\begin{array}{l}21 \text { Left } \\
32 \text { Right }\end{array}$ & $\begin{array}{l}15 \text { Lateral } \\
38 \text { Medial }\end{array}$ & NR & NR & 21 & NR & $\begin{array}{c}21.9 \\
\text { months }\end{array}$ \\
\hline Nakata et al. ${ }^{28}$ & 35 & $29(88 \%)$ & $\begin{array}{l}18 \text { months } \\
(12-26)\end{array}$ & $\begin{array}{l}33 \text { initially, } 6 \\
\text { lost to } \\
\text { follow-up }\end{array}$ & $25.5(16-42)$ & 17 & NR & $\begin{array}{l}18 \text { Lateral } \\
11 \text { Medial }\end{array}$ & $\begin{array}{c}\text { Type A: } 2 \\
\text { Type B 1: } 6 \\
\text { Type B2: } 8 \\
\text { Type C: } 9 \\
\text { Type D: } 4\end{array}$ & 0 & 21 & NR & 8 months \\
\hline Chen et al. ${ }^{29}$ & 7 & $7(100 \%)$ & NR & NR & NR & NR & NR & $\begin{array}{l}7 \text { Lateral } \\
0 \text { Medial }\end{array}$ & NR & NR & NR & NR & NR \\
\hline
\end{tabular}

NOTE. None of the studies reported on tear site.

ACLR, anterior cruciate ligament reconstruction; NR, not recorded. 
Table 5. Study Surgical Techniques and Protocols

\begin{tabular}{|c|c|c|c|c|c|c|c|}
\hline Study & Fixation Approach & Sutures Used & $\begin{array}{l}\text { Mean No. of } \\
\text { Sutures }\end{array}$ & Adjuncts Used & $\begin{array}{c}\text { Weight-Bearing } \\
\text { Restrictions }\end{array}$ & $\begin{array}{c}\text { ROM } \\
\text { Restrictions } \\
\end{array}$ & $\begin{array}{l}\text { Return to } \\
\text { Sport }\end{array}$ \\
\hline Song et al. ${ }^{18}$ & $\begin{array}{l}\text { Arthroscopic, all- } \\
\text { inside, side-to-side } \\
\text { approach }\end{array}$ & No. 0 PDS & $\mathrm{NR}$ & None & NWB, 4 weeks & $\begin{array}{l}0 \text {-90 for } 4 \\
\text { weeks }\end{array}$ & $\mathrm{NR}$ \\
\hline $\begin{array}{l}\text { Anderson } \\
\text { et al. }{ }^{19}\end{array}$ & $\begin{array}{c}\text { Arthroscopic, } \\
\text { inside-out; all-inside } \\
\text { technique in some }\end{array}$ & NR & $1.9 \pm 1.1$ & None & NR & NR & NR \\
\hline $\begin{array}{l}\text { Haklar } \\
\text { et al. }^{21}\end{array}$ & $\begin{array}{l}\text { arthroscopic, inside- } \\
\text { out approach, using } \\
\text { zone-specific curved } \\
\text { cannula }\end{array}$ & $\begin{array}{c}\text { Nos. O and } 2 \\
\text { ETHIBOND sutures } \\
\text { (Ethicon) }\end{array}$ & $\begin{array}{l}2.4 \text { superior, } \\
2.8 \text { inferior }\end{array}$ & None & NWB, 6-8 weeks & $\begin{array}{l}\text { Immobilized for } \\
\text { 6-8 weeks }\end{array}$ & 4-5 months \\
\hline Wu et al. ${ }^{23}$ & $\begin{array}{l}\text { arthroscopic, inside- } \\
\text { out (7) or all-inside } \\
\text { technique (16) or } \\
\text { hybrid (1) }\end{array}$ & No. 2 Ethicon & NR & $\begin{array}{l}\text { Platelet-rich fibrin } \\
\text { matrix ( } 3 \text { ) }\end{array}$ & NWB, 4 weeks & $\begin{array}{l}\text { 0-90 for } 4 \\
\text { weeks }\end{array}$ & 4 months \\
\hline $\begin{array}{l}\text { Cinque } \\
\text { et al. }^{24}\end{array}$ & $\begin{array}{l}\text { Two-tunnel, } \\
\text { transtibial pullout } \\
\text { repair }\end{array}$ & $\begin{array}{c}\text { No. } 2 \text { nonabsorbable } \\
\text { suture } \\
\text { (ULTRABRAID); } 2- \\
0 \text { non-absorbable } \\
\text { horizontal mattress } \\
\text { to reinforce }\end{array}$ & NR & $\begin{array}{l}\text { Marrow-venting } \\
\text { procedure (10) }\end{array}$ & NWB, 6 weeks & $\begin{array}{l}0-90 \text { for } 2 \\
\text { weeks, then } \\
\text { progress as } \\
\text { tolerated }\end{array}$ & 4 months \\
\hline Tsujii et al. ${ }^{25}$ & $\begin{array}{l}\text { arthroscopic, inside- } \\
\text { out (29) or all-inside } \\
\text { (12) technique }\end{array}$ & $\begin{array}{l}\text { No 2-0 braided } \\
\text { polyester suture }\end{array}$ & NR & None & NWB, 3-4 weeks & $\begin{array}{l}\text { Immobilized for } \\
1 \text { week, then } \\
\text { ROM started }\end{array}$ & 8-9 months \\
\hline $\begin{array}{l}\text { Nakata } \\
\text { et al. }^{28}\end{array}$ & $\begin{array}{l}\text { arthroscopic inside } \\
\text { out }\end{array}$ & $\begin{array}{l}\text { 2-0 ETHIBOND } \\
\text { sutures }\end{array}$ & 5 or 6 & $\begin{array}{l}\text { autogenous fibrin } \\
\text { clot (unless } \\
\text { concomitant } \\
\text { ACLR) }\end{array}$ & $\begin{array}{l}\text { NWB, } 4 \text { weeks, } \\
\text { PWB until } 6 \\
\text { weeks, }\end{array}$ & & 6 months \\
\hline Chen et al. ${ }^{29}$ & NR & NR & NR & $\mathrm{NR}$ & NR & NR & \\
\hline
\end{tabular}

CPM, continuous passive motion; NR, not recorded; NWB, non-weight-bearing; PDS, p-dioxanone ROM, range of motion; UHMW, ultra high molecular weight polyethylene.

Among the concomitant operations reported with meniscal repair, anterior cruciate ligament reconstruction (ACLR) was the most common (141 of 221 knees that explicitly reported on concomitant operations).

\section{Repair Technique, Adjuvant Therapy, and Rehabilitation}

Repairs were performed via multiple approaches (Table 5). In 1 series, $12.2 \%(27 / 221)$ of cases were performed via an arthroscopic-assisted, 2-tunnel transtibial pullout technique. ${ }^{24}$ Of the other $87.8 \%$ (194/221) of repairs, $82(37 \%)$ were performed via the arthroscopic-assisted inside-out technique, 103 (47\%) using all-inside arthroscopic, and $1(0.5 \%)$ using a hybrid arthroscopic-assisted inside-out/all-inside repair. Anderson et al., ${ }^{19}$ including 8 (3.6\%) knees, reported the use of arthroscopy for repair but did not specify how many knees fell into each manner of approach (Table 1). 
Table 6. Outcome Assessments Used

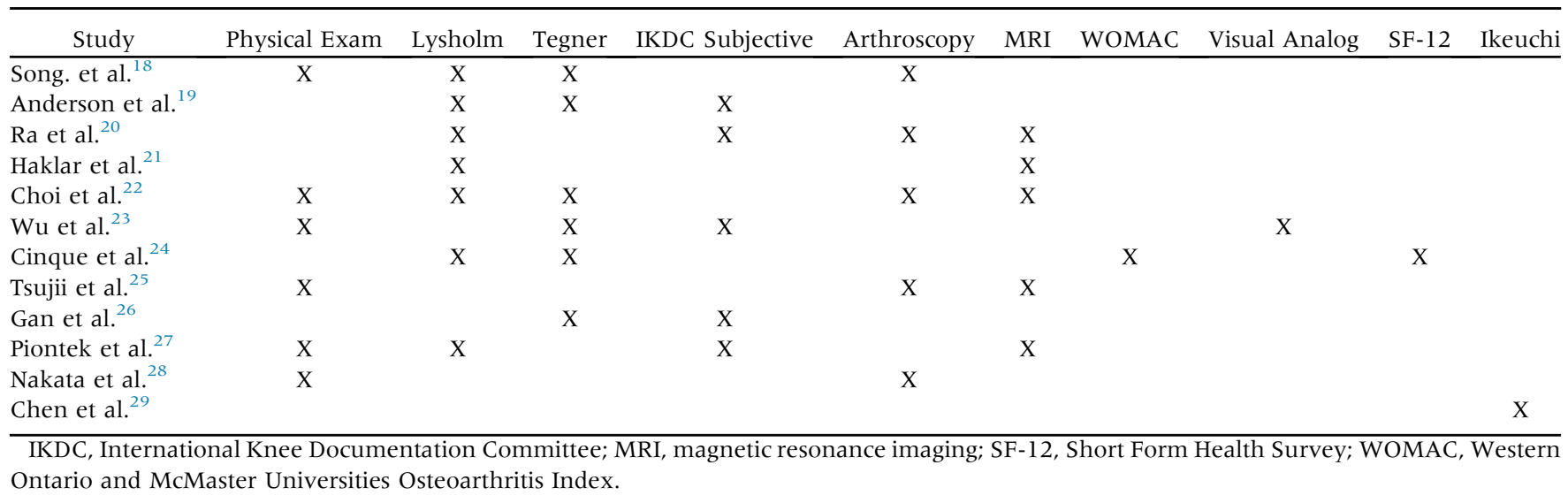

Studies differed in the type of suture material and adjunct methods (Table 5). The most commonly used suture of those reported was the Number 2-0 ETHIBOND suture in a horizontal fashion $(73.7 \%)$. Other sutures used were the No. 2 ULTRABRAID nonabsorbable suture $(12.7 \%)$, No. 0 polydioxanone $(7.0 \%)$, and No. 1 polydioxanone $(6.6 \%)$. Regarding adjuvants to meniscal repair, $35.4 \%(86 / 243)$ reported the use at least one adjunct technique. Of these, $61.6 \%$ reported the use of a collagen membrane wrapping with bone marrow injection, $23.3 \%$ of them used a fibrin clot, $11.6 \%$ used marrow-venting technique, and 3.5\% were performed with the use of a platelet-rich fibrin matrix.

All of the included studies restricted weight-bearing and range of motion to some degree postoperatively; however, no single postoperative restrictions predominated (Table 5). Most studies included non-weightbearing precautions for at least 4 weeks, and at least 4 months before allowing return to sport. Postoperatively, $26.7 \%(65 / 243)$ used MRI for the evaluation of healing, whereas $33.3 \%(81 / 243)$ of knees used second-look arthroscopy, indicated for a number of reasons, to assess for meniscal healing. Those reasons include, removal of screws, plates, or washers, dissatisfaction with the results of the operation, MRI indicating partial healing, or determining the true healing status before return to sport,

\section{Patient-Reported Outcomes}

Patient-reported outcomes tool varied among the included studies (Table 6), but qualitative improvement from preoperative to postoperative scores was noted (Table 7). Seven studies used the Lysholm scores to assess outcomes, Preoperative scores ranged from 47 to 73.7 and postoperative scores ranged from 86.4 to 95.6. Five studies used International Knee Documentation Committee Subjective scores as am outcomes measure, with a preoperative range of 39.8 to 57 and a postoperative range of 79.1 to 92 . One study reported the postoperative Ikeuchi score and demonstrated $42.9 \%$ good/excellent outcomes with this measure. Similarly, l study reported on preoperative and postoperative visual analog score, which decreased from 5.8 to 0.8 . A lone study evaluated outcomes using the SF-12 Physical Component Summary and saw improvement from preoperative to postoperative time points from 37 to 55 . In addition, a single study reported on outcomes using the Western Ontario and McMaster Universities Osteoarthritis Index, demonstrating an improvement from preoperative to postoperative measures from 37 to 4 . Six studies reported activity level using the Tegner Activity Scale Preoperative scores ranged from 1 to 4 and postoperative scores ranged from 4.7 to 6.7.

\section{Healing Rates}

Seven studies examined healing rates following repair of radial meniscus tears using second-look arthroscopy or MRI. Six of these papers categorized healing in terms of complete healing, partial healing, and failure to heal. Complete healing was reported in $60 \%$ to $100 \%$ of patients, partial healing in 0 to $57 \%$ of patients, and failure to heal was noted in 0 to $13 \%$ of patients (Table 8). One study used follow-up MRI as a means of evaluating healing rates and noted a "good outcome" in $85 \%(39 / 46)$ of their population based on WORMS Classification $(\leq 1)$.

\section{Other Outcomes}

Meniscal extrusion was assessed in three studies. Extrusion of the meniscus at the repair location was described in 2 studies, in a total of 3 patients. ${ }^{22,23}$ Tsujii et al. ${ }^{25}$ measured extrusion among all patients in their study, demonstrating clinically significant extrusion in the sagittal plane in comparison with the control group.

\section{Complications}

Complications were reported in 5 of the 12 studies. Of the 5 studies that reported complications or reoperations, 3 of the studies indicated that the complications 


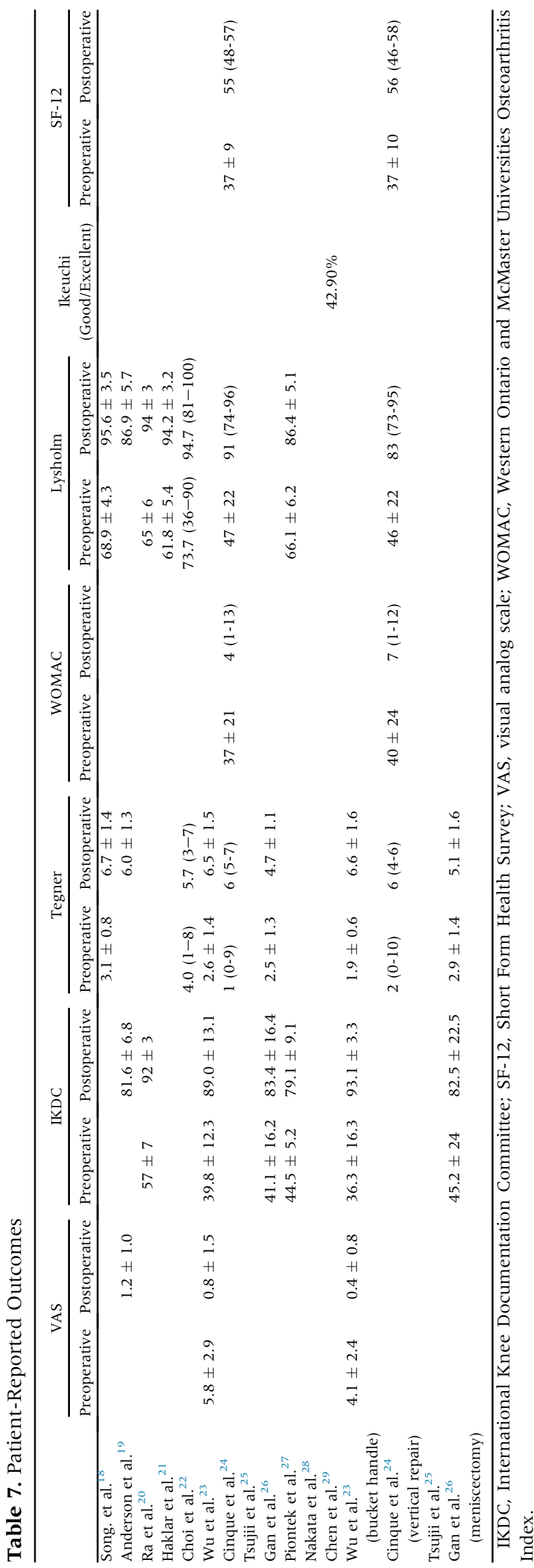

were a result of the index procedure. Wu et al. ${ }^{23}$ revealed that a patient developed arthrofibrosis and required lysis of adhesions 2 months after the initial repair, whereas Cinque et al. ${ }^{24}$ described that a patient sustained delamination of the medial femoral condyle and underwent microfracture, removal of loose bodies, and lysis of adhesions. Piontek et al. ${ }^{27}$ described that MRI revealed a cyst located near the T-fix anchor in $62 \%$ of cases, however the presence of a cyst had no correlation with International Knee Documentation Committee, Barret criteria, or cumulative Whole-Organ Magnetic Resonance Imaging Score (WORMS) results. Of the 2 studies that described complications requiring reoperations, it was determined in all cases that the original repair was seen to have healed.

\section{Discussion}

The most impactful discovery made through this study is that repair of radial meniscus tears produces good patient-reported outcomes and a low failure rate. Across all included studies, patient-reported outcomes improved in every included metric. Further, healing rates observed in those studies in which they were high with low reported failure rates.

Radial meniscus tears are a unique classification of tears that have been demonstrated to have particular poor prognosis. ${ }^{14}$ Studies have demonstrated that these tears effectively render the meniscus unfunctional and provided equivalent clinical outcomes to that of having no meniscus at all. ${ }^{33}$ Historically speaking, radial meniscus tears have largely been managed by methods of meniscectomy, either partial or total. A study by Zhang et al. ${ }^{34}$ used 3-dimensional models to demonstrate a significant increase in compressive and sheer stresses on the knee joint following meniscectomy, specifically in cases of preceding radial meniscus tears. Using a finite element model of the knee joint, they were able to conclude that following meniscectomy, the increase in stress predominated at the medial aspect of both cartilages within the knee. As many similar studies continue to emerge demonstrating deleterious effects of removing meniscal tissue, there has been an associated shift in paradigm of managing all meniscal injury, including radial type tears. ${ }^{5,35}$

In response to the growing favor of preserving meniscal tissue, various techniques have emerged as mainstays in the repair of radial meniscus tears and the majority of these have been included in this review. Among these studies, the majority are arthroscopic techniques, of which inside-out, all-inside, or hybrid techniques are described. In addition, one study included the use of an open, trans-tibial, 2-tunnel pullout technique. Based on reported results, one technique cannot be concluded to be superior over another in terms of outcomes and management of these types of tears. However, it does reveal that successful 
Table 8. Healing Rates

\begin{tabular}{|c|c|c|c|c|c|}
\hline Study & Evaluation Method & Complete Healing & Partial Healing & Failure & Total \\
\hline$\overline{\text { Song et. } \mathrm{al}^{18}}$ & Second-look arthroscopy & $9(60 \%)$ & $4(27 \%)$ & $2(13 \%)$ & 15 \\
\hline Ra et al. ${ }^{20}$ & Second-look arthroscopy & $6(86 \%)$ & $1(14 \%)$ & $0(0 \%)$ & 7 \\
\hline Tsujii et al. ${ }^{25}$ & Second-look arthroscopy & $18(60 \%)$ & $9(30 \%)$ & $3(10 \%)$ & 30 \\
\hline Nakata et al. ${ }^{28}$ & Second-look arthroscopy & $19(66 \%)$ & $8(28 \%)$ & $2(7 \%)$ & 29 \\
\hline Haklar et al. ${ }^{21}$ & MRI & $5(100 \%)$ & $0(0 \%)$ & $0(0 \%)$ & 5 \\
\hline Choi et al. ${ }^{22}$ & MRI & $5(36 \%)$ & $8(57 \%)$ & $1(7 \%)$ & 14 \\
\hline
\end{tabular}

MRI, magnetic resonance imaging.

reparation of a radial tear can be achieved through the use of a number of different approaches.

This is not the first systematic review on this topic. In a systematic review completed by Moulton et al. ${ }^{15}$ published in 2016, the authors concluded positive short-term outcomes in radial meniscus repair at an average of 38.4 months postoperation. While this review presented thorough and valuable evidence for the effectiveness of radial meniscus repairs, several additional studies have since been published that demanded further review of this topic. This recent literature allowed us to adequately assess healing rates in this particular population. Further, a recently published review by Lee et al. ${ }^{16}$ solely examined medial meniscus posterior root tears. This investigation concluded that repairs in this population led to clinical improvement, while the non-repair group had more variability in outcome. The authors stressed the importance of using a selection criterion to choose proper candidates for repair. An additional review has been completed from a biomechanical perspective as well. Alentorn-Geli et al. $^{36}$ described no significant difference between outside-in, inside-out and all-inside repairs load to failure or stiffness, displacement, or site of failure.

In light of our current review, as well as the entirety of the available literature assessing outcomes of radial meniscus tears and their repairs, much still remains unknown. First and foremost, with this current review including an average follow up of just 35 months, the long term outcomes associated with these procedures remains uninvestigated. Further, comparing techniques of radial meniscus repair in terms of outcomes and failure rates requires more investigation as well.

\section{Limitations}

Our study is not without limitations. Limitations of our review include the use of small, nonrandomized and noncomparative studies. Optimal study type would be those that are large, comparative, and of a high level of evidence. Our review yielded just 3 studies that contained a control group (there were no randomized controlled studies). Six of the 12 studies were retrospective, noncomparative case series, 5 were retrospective cohorts, and there was 1 prospective cohort study. In analyzing the Coleman Methodology
Scores for the 12 included studies, a lack of high-level studies was also observed. The mean score for included papers was 46.8, range 26-60 (Table 4). Four of $12(33 \%)$ studies received a score between 55 and 69 indicating fair studies, with the remaining 8 of 12 $(75 \%)$ studies falling below a score of 55 indicating poor studies. Areas largely contributing to the mean score include study size, the type of study, and scores related to subject recruitment and selection. Six of the 12 studies $(50 \%)$ did not include a sufficient number of patients to earn a point based on size, and due to a lack of randomization across of all studies, none of them meet satisfaction for subject recruitment, utilizing independent investigators, unbiased selection criteria, and recruitment rate.

Furthermore, a major limitation is the inclusion of, and inability to separate as a subgroup, ACL, ACLR, and other concomitant procedures among some patients in included studies. Given well-published increased healing rates after meniscal repair in patients undergoing concomitant ACLR, a subgroup analysis of these patients would be helpful. However due to limited subgroup data availability in each study, a subgroup analysis was not possible. A similar limitation is seen by inclusion and combination of both medial and lateral meniscal injuries as one group. The large number of different outcomes tools precludes pooling of data from the included studies and the lack of objective assessment of meniscus repair healing in many studies (those that rely on a clinical assessment of results) may lead to an underestimation of repair failure risk. Finally, this study is limited by a relatively short mean follow-up period. A longer follow-up period is necessary to observe potential complications arising in association with these procedures, such as osteoarthritic changes. Further, this would help illuminate whether the reported healing rates are exclusively anatomical in nature, or if they restore the true biomechanical function of the meniscus as well. A number of studies have demonstrated the potential for restoring native function with meniscus repair. ${ }^{2,37}$

\section{Conclusions}

Patient-reported outcomes after repair of radial meniscus repair with and without ACL reconstruction 
are encouraging, with high patient-reported outcomes scores reported at final postoperative follow-up when compared with preoperative scores, across a variety of outcomes scoring systems. Among all meniscus repairs assessed for healing, the majority demonstrated at least some healing with an overall low rate of failure.

\section{References}

1. Danso EK, Oinas JMT, Saarakkala S, Mikkonen S, Töyräs J, Korhonen RK. Structure-function relationships of human meniscus. J Mech Behav Biomed Mater 2017;67: 51-60.

2. Makris EA, Hadidi P, Athanasiou KA. The knee meniscus: Structure-function, pathophysiology, current repair techniques, and prospects for regeneration. Biomaterials $2011 ; 32: 7411-7431$.

3. Bilgen B, Jayasuriya CT, Owens BD. Current concepts in meniscus tissue engineering and repair. Adv Healthc Mater 2018;7:e1701407.

4. Logerstedt DS, Snyder-Mackler L, Ritter RC, Axe MJ, OSotAPT Association. Knee pain and mobility impairments: Meniscal and articular cartilage lesions. J Orthop Sports Phys Ther 2010;40:A1-A35.

5. Beaufils PPN. Management of traumatic meniscal tear and degenerative meniscal lesions. Save the meniscus. Orthop Traumatol Surg Res 2017;103:S237-S244.

6. Allen PR, Denham RA, Swan AV. Late degenerative changes after meniscectomy. Factors affecting the knee after operation. J Bone Joint Surg Br 1984;66:666-671.

7. McDermott ID, Amis AA. The consequences of meniscectomy. J Bone Joint Surg Br 2006;88:1549-1556.

8. Petty CA, Lubowitz JH. Does arthroscopic partial meniscectomy result in knee osteoarthritis? A systematic review with a minimum of 8 years' follow-up. Arthroscopy $2011 ; 27: 419-424$.

9. Abrams GD, Frank RM, Gupta AK, Harris JD, McCormick FM, Cole BJ. Trends in meniscus repair and meniscectomy in the United States, 2005-2011. Am J Sports Med 2013;41:2333-2339.

10. Hevesi M, Krych AJ, Kurzweil PR. Meniscus tear management: Indications, technique, and outcomes. Arthroscopy 2019;35:2542-2544.

11. Kurzweil PR, Lynch NM, Coleman S, Kearney B. Repair of horizontal meniscus tears: A systematic review. Arthroscopy 2014;30:1513-1519.

12. Mordecai SC, Al-Hadithy N, Ware HE, Gupte CM. Treatment of meniscal tears: An evidence based approach. World J Orthop 2014;5:233-241.

13. Vaquero-Picado A, Rodríguez-Merchán EC. Arthroscopic repair of the meniscus: Surgical management and clinical outcomes. EFORT Open Rev 2018;3:584-594.

14. Bedi A, Kelly N, Baad M, et al. Dynamic contact mechanics of radial tears of the lateral meniscus: Implications for treatment. Arthroscopy 2012;28:372-381.

15. Moulton SG, Bhatia S, Civitarese DM, Frank RM, Dean CS, LaPrade RF. Surgical techniques and outcomes of repairing meniscal radial tears: A systematic review. Arthroscopy 2016;32:1919-1925.

16. Lee JK, Jung M, Yang JH, et al. Repair versus nonrepair of medial meniscus posterior root tear: A systematic review of patients' selection criteria, including clinical and radiographic outcomes. Medicine (Baltimore) 2020;99:e19499.

17. Moher D, Liberati A, Tetzlaff J, Altman DG. Preferred reporting items for systematic reviews and meta-analyses: The PRISMA statement. PLoS Med 2009;6:e1000097.

18. Song HS, Bae TY, Park BY, Shim J, In Y. Repair of a radial tear in the posterior horn of the lateral meniscus. Knee 2014;21:1185-1190.

19. Anderson L, Watts M, Shapter O, et al. Repair of radial tears and posterior horn detachments of the lateral meniscus: Minimum 2-year follow-up. Arthroscopy 2010;26:1625-1632+e1212.

20. Ra HJ, Ha JK, Jang SH, Lee DW, Kim JG. Arthroscopic inside-out repair of complete radial tears of the meniscus with a fibrin clot. Knee Surg Sports Traumatol Arthroso 2013;21:2126-2130.

21. Haklar U, Kocaoglu B, Nalbantoglu U, Tuzuner T, Guven O. Arthroscopic repair of radial lateral menicus tear by double horizontal sutures with inside-outside technique. Knee 2008;15:355-359.

22. Choi NH, Kim TH, Son KM, Victoroff BN. Meniscal repair for radial tears of the midbody of the lateral meniscus. Am J Sports Med 2010;38:2472-2476.

23. Wu IT, Hevesi M, Desai VS, et al. Comparative outcomes of radial and bucket-handle meniscal tear repair: A propensity-matched analysis. Am J Sports Med 2018;46: 2653-2660.

24. Cinque ME, Geeslin AG, Chahla J, Dornan GJ, LaPrade RF. Two-tunnel transtibial repair of radial meniscus tears produces comparable results to inside-out repair of vertical meniscus tears. Am J Sports Med 2017; 45:2253-2259.

25. Tsujii A, Yonetani Y, Kinugasa K, et al. Outcomes more than 2 years after meniscal repair for radial/flap tears of the posterior lateral meniscus combined with anterior cruciate ligament reconstruction. Am J Sports Med 2019;47: 2888-2894.

26. Gan JZW, Lie DTT, Lee WQ. Clinical outcomes of meniscus repair and partial meniscectomy: Does tear configuration matter? J Orthop Surg 2020;28.

27. Piontek T, Ciemniewska-Gorzela K, Naczk J, et al. Complex meniscus tears treated with collagen matrix wrapping and bone marrow blood injection: A 2-year clinical follow-up. Cartilage 2016;7:123-139.

28. Nakata K, Kanamoto T, Mae T, et al. New technique of arthroscopic meniscus repair in radial tears. In: Doral NM, Tandogan RN, Mann G, Verdonk R, eds. Sports injuries: Prevention, diagnosis, treatment, and rehabilitation. Springer Berlin Heidelberg, 2012;305-311.

29. Chen HC, Yang CB, TC F, Ma HL, Liu CL, Huang TF. Management and outcome of discoid meniscus tears. Formosan J Musculoskel Disord 201 1;2:45-48.

30. Coleman BD, Khan KM, Maffulli N, Cook JL, Wark JD. Studies of surgical outcome after patellar tendinopathy: Clinical significance of methodological deficiencies and guidelines for future studies. Victorian Institute of Sport Tendon Study Group. Scand J Med Sci Sports 2000;10:2-11.

31. Burns PB, Rohrich RJ, Chung KC. The levels of evidence and their role in evidence-based medicine. Plast Reconstr Surg 2011;128:305-310. 
32. Sterne JA, Hernán MA, Reeves BC, et al. ROBINS-I: A tool for assessing risk of bias in non-randomised studies of interventions. BMJ 2016;355:i4919.

33. Pache S, Aman ZS, Kennedy M, et al. Meniscal root tears: Current concepts review. Arch Bone Joint Surg 201 8; 6:250-259.

34. Zhang AL, Miller SL, Coughlin DG, Lotz JC, Feeley BT. Tibiofemoral contact pressures in radial tears of the meniscus treated with all-inside repair, inside-out repair and partial meniscectomy. Knee 2015;22:400-404.

35. Seil R, Becker R. Time for a paradigm change in meniscal repair: Save the meniscus! Knee Surg Sports Traumatol Arthrosc 2016;24:1421-1423.
36. Alentorn-Geli E, Choi JHJ, Stuart JJ, et al. Inside-out or outside-in suturing should not be considered the standard repair method for radial tears of the midbody of the lateral meniscus: A systematic review and metaanalysis of biomechanical studies. J Knee Surg 2016;29: 604-612.

37. LaPrade CM, Jansson KS, Dornan G, Smith SD, Wijdicks CA, LaPrade RF. Altered tibiofemoral contact mechanics due to lateral meniscus posterior horn root avulsions and radial tears can be restored with in situ pull-out suture repairs. J Bone Joint Surg Am 2014;96: 471-479. 